\title{
THE ROLE OF FLIGHT SIMULATION IN FLIGHT TRAINING OF PILOTS FOR CRISIS MANAGEMENT
}

\author{
Dragan A. Lazić ${ }^{*}$, \\ Vladimir Grujić2 \\ Marko Tanasković3 \\ 1PhD Student, \\ Singidunum University, \\ Belgrade, Serbia \\ ${ }^{2}$ Higher School of Professional \\ Studies „Čačak", \\ Belgrade, Serbia \\ ${ }^{3}$ Singidunum University, \\ Belgrade, Serbia
}

\begin{abstract}
:
Every day over 102.000 commercial passenger flights take place on a global scale above our heads. Because of that many questions arise in the areas of safety and security in massive air traffic. If airlines use crisis management, any activity concerning the preparation of the crew and the aircraft for a particular task - flight gets more significance and importance. During the flight, the pilot - the captain of the aircraft, is the key person of any company activity that includes transport of people and goods, and that is the reason why a pilot's psycho-physical abilities and flying performance must be constantly checked, evaluated and improved. In a plane crash near North Macedonia's capital city Skopje, the aviation investigators discovered the number of serious failures in pilot training that led to the fall of a private plane Cessna 340. The investigation revealed that although the pilot was certificated to fly in instrument meteorological conditions, his actions in the air indicate that he was not well trained. European and American aviation authorities have clear legal regulations regarding the training and certification for individual flight categories as well as a categorized simulation technique where pilots exercise before they get one of the flying categories. Flight simulators play an essential role in the training of the future pilots for both visual and instrumental flight conditions.
\end{abstract}

Keywords:

Crisis management in aviation, Airlines, Flight training, Flight Simulators.

\section{INTRODUCTION}

Because of the specificity of this work and regarding the still poorly known issues about which the work is, in this introduction we will present the cross section of the events which will lead to the situation of crisis of the aircraft "Cessna 340", on the flight Thessaloniki - Innsbruck. With the absence of the prompt reaction of the pilot to transform the flight from the visual flight to the instrumental one, the procedures for solving the situations of crises will not be applied consequently, because, upon entering clouds it will hit a hill, which will, unfortunately, cause its fall and the death of the pilot and passengers [1].

The Austrian aircraft "Cessna 340", flown by the Austrian professional pilot with the license for instrument flight took off from Thessaloniki to Innsbruck. The wife of the pilot was in the plane as a passenger. 
The weather conditions over North Macedonia were bad. The clouds were low with precipitation. The flight according to the rules for a visual flight could hardly be feasible. Nevertheless, the pilot made the decision to take off. Somewhere above Skopje he realized that he would fly into the clouds, so he asked for the approval of the flight control in Skopje to lower the height of the flight. Since he fulfilled the plan of the flight by the regulations for a visual flight, he got such the approval. He started to lower the height although he was warned by the flight control of the thickness of the cloud layer. Although the pilot was trained for instrumental flight, he decided to continue the visual flight.

By descending under the clouds, he tried to continue his visual flight, but soon he entered a snowstorm. In the conditions of reduced visibility, he crashed a hill. The propeller of the right engine hooked the top of the rock. The wing was broken together with the engine. The pilot and his wife were killed, and the plane was destroyed.

Namely, during a visual flight, a pilot determines his position according to a visible earth horizon and leads the navigation by visible landmarks on earth. During an instrument flight, a pilot determines his position according to the artificial horizon and leads the navigation by radio navigation instruments on earth, completely excluding physical feelings and their false signals. The transfer from one type of flying to the other is a very complex process, which is proved by a great number of accidents that happen to the pilots who have passed from a visual flight to an instrument flight.

The pilot of the Austrian aircraft was trained for such flights, but during the last year he mostly flew visually, as a pilot of agricultural aviation.

Being conscious of the difficulties of passing from a visual flight to an instrument flight, he made the wrong decision, the situation of crises finished accidentally. The aviation investigation board of the authorities of North Macedonia wrote in their conclusion: Insufficient training of the pilot for instrumental flight is the main reason of the crash of the "Cessna 340", flown by the Austrian pilot on the line Thessaloniki - Innsbruck.

\section{WHY FLIGHT SIMULATORS?}

Flying a plane is one of the most difficult and most complex jobs a man has ever done. A pilot has to have necessary psychical and physical predispositions and great knowledge because he manages an aircraft in the third dimension of the space.
Those who want to do that profession are demanded to have top qualities that are not the conditions for doing many other professions.

According to an American study from the beginning of the $1960 \mathrm{~s}$, it was proved that out of 12.429 young men capable for military service, according to the criteria of medical boards for flying, only a thousand of them, or eight out of a hundred, were admitted to the schools for military pilots. The growth of the prices of planes and the price of the training had crucial influence to the increasingly rigorous selection of the candidates.

In the book "Outliers: The Story of Success", the author Malcolm Gladwell claims that the key to achieving world-class expertise in any skill, is, to a large extent, a matter of practicing the correct way, for a total of around 10,000 hours. According to the study of the State University of Florida, the professor Anders Ericsson interprets this "rule" in the way that the success in a certain activity is based not so much on the talent as on much practice. It would be wonderful if all pilots could have 10.000 hours of real flight, but it probably is not feasible for those ones who fly by recreation. No matter how much we want that, most of the pilots all over the world do not have enough time and finances for such the level of activities[2]. For that reason, flight simulators are key instruments which provide training and learning of pilots in safe conditions on earth. A well documented use of simulation in air transport for training clearly indicates both advantages and values of such approach. Fortunately, for all those who fly, current simulation technologies provide endless opportunities for the development of the knowledge and skills, and also the improvement and learning the procedures necessary for pilots to have a safe and secure flight.

"A flight simulator is a device that artificially creates a flight of an aircraft and the environment in which it flies, for the purpose of training of pilots or other purposes. That includes the elaboration of the equations that regulate how planes fly, how they react to the applications of flight control, effects of other aircraft systems and how an aircraft reacts to external factors such as air density, turbulence, current vibrations, clouds, precipitation etc. Flight simulation is used for various reasons, including trainings for flight (mostly of pilots) trainings and the development of an aircraft itself and the investigation of the characteristics of a plane and the control of management quality" [3]. 


\section{TYPES OF FLIGHT SIMULATORS}

The pilots in the air companies are able to use sophisticated simulators with three axes motion, for training, certification and testing the knowledge. Many passengers could be surprised if they knew that many maneuvers are firstly examined on simulators and never in reality until the situation of crisis itself.

Modern devices for training in aviation (ATDs) provide significant possibilities to pilots in the process of training, to learn basic skills and improve advanced skills of flying a plane in all the systems in aviation and to use available time in the most efficient and payable way.

Whether it is about visual or instrumental conditions for flight, aviation relies very much on procedures. In the conditions when a pilot beginner who is getting acquainted with basic skills and procedures that he must learn on a new plane or simply achieve a higher degree of training on the aircrafts that he already uses, simulation technologies can help to maintain or improve the abilities of flying a plane, i.e. the pilot to improve a precise control of the instruments, flight height and air speed [4].

No matter whether it is about a beginner or an experienced traffic pilot, time can be well used on flight simulators in order to improve the technique and become a pilot. The advantages are indisputable, because of which the Federal Aviation Administration (FAA) increasingly work on the issue to help companies create modern technologies for the improvement of flight safety. In addition to the data for the training and certification, the analysis enabled new, more logical regulations for the categorization of the devices for flight training [5]. Several various devices classified in many categories are used in modern flight trainings. Basically, the Federal Aviation Administration (FAA) of the USA and the authorities of the European Union (EASA - European Aviation Safety Agency) have accepted different classifications and levels of flight simulators.

Flight simulators approved by the Federal Aviation Administration (FAA):

The Aviation Training Device or ATD is the most frequent option for flight training in general aviation on small planes. In 2008, the FAA issued the Approval for application of aviation training devices and their use for training and practice, which helped in defining the differences between a home flight simulator in the form of video games and an aviation training device.
That was done by introducing two new terms: Basic ATD and Advanced ATD level of aviation training device, together with the appropriate standards of performances and directions for users.

The Basic aviation training device: Although it is similar to the software intended for home video games, the Basic aviation training device generally has more improved hardware and software functions which enable the Federal Aviation Administration to approve its use for training, practice and testing the qualification of a pilot. The application is limited to the certification for a pilot for obtaining pilot licenses for recreation, sports and private pilots, as well as the license for instrument flight in the aspect of a preparation for a flight. However, the Basic aviation training device cannot be used for testing the qualification for flying in instrumental conditions [6].

The demands that every Basic aviation training device has to fulfill are in the parameters of aircraft performances (flight speed, maximum climbing speed, cruise speed etc.). The results have to be comparable to a representative plane [7].

The Advanced aviation training device: as the name itself says, there are many standards for the Advanced aviation training device, together with the criteria of design which demand more realistic appearance and the feeling of a plane. Firstly, the Advanced aviation training device has to fulfill all the criteria for approving the Basic aviation training device as well as to unite additional properties and reliability of the system that significantly exceed the Basic aviation training device.

Among these regulations it includes the unification of the "representatives" of ergonomics in the category and class of airplane flight cabin, GPS system with mobile mapping system, a two-axis autopilot, an independent visual system which can provide real visual and instrument conditions for flying, a separate room for the instructor and the ability of simulation all emergency procedures which are contained in a pilot manual for flying a plane [8].

A flight training device FTD: The following categories are flight training devices or FTD. These devices are designed to represent a specific configuration of an airplane and depending on the level of the qualification of a flight training device, they can include a close cockpit and real visual situation. They are not always capable to realize a movement, but they are sophisticated enough to provide the training for preparation of a pilot to obtain the certificate for commercial and air transport, as well as other estimations. 
Flight training devices are frequently used at universities and colleges that educate personnel in aviation. Aviation industry also use these devices a great deal for training new candidates before getting employed or by changing the professional title from a copilot to a captain , as well as for a transit training (for example the plane Boeing B737 to Boeing B747). Flight training devices are divided into the levels from 4 to 7 . The levels 4, 5, 6, refer to fixed devices while the level 7 refers to helicopters. By the way, the levels 1 to 3 apply to older devices which are no longer used, or which are transferred to lower categories as Aviation Training Devices.

A Full Motion Flight Simulator FFS: is a term used by civil aviation organs for a high technical level of flight simulators. Such advanced flight training simulators are present both in the division at the Federal Aviation Administration USA and the European Aviation Safety Agency.

There are currently four levels of full motion flight simulators, from the level A to the level D. The level D is the highest and is certified for training the pilots with zero classes of flight experience on a specific type of aircraft.

This standard is used for initial and transitional flight training in commercial air traffic. Initial training is for the pilots who transfer to a new type of a plane, and the transitional training is for all other commercial pilots who have to realize it in regular intervals every six months in order to maintain their qualifications for flying in air traffic

Flight simulators approved by the European Aviation Safety Agency (EASA):

A Full Motion Flight Simulators FFS, a full motion platform, are approved by American and European aviation authorities as a common project so their certification and identification of various levels goes in the same direction as it has been said before.

European requirements in the certification of flight simulators are a little more strict on the lower levels of the platforms they identify[9]: As the lowest level platform of flight training simulators and navigation procedures:- EASA FNPT Level I; EASA FNPT Level II; EASA FNPT Level III- MCC- It is not a real certified level platform but it is approved within the previous three levels with special additions for realization of Multi Crew Cooperation Training. Flight simulators are similar to American flight training devices, with the fact that the difference is again in the level classification: EASA FTD Level 1; EASA FTD Level 2; EASA FTD Level 3- only for helicopters.

\section{The latest flight simulators}

The biggest flight simulator in the world is Vertical Motion Simulator (VMS) in the research center NASA Ames, south of San Francisco. The system can realistically present a vertical movement- moving to 60 feet and to demonstrate the vibration of simulator. This design enables fast transition of various types of aircrafts on which the flight simulations will be done. The possibilities of simulation move from commercial and military airplanes to the Space Shuttle [10].

\section{CRISIS MANAGEMENT IN AVIATION}

The first decade of the third millennium, for most theoreticians, is the decade of global crisis which covers politics, economy, education, traffic, energetic, or to make it simpler, it covers completely all social activities. Although humans nowadays have fascinating knowledge and abilities, crises of immerse dimensions happen for the reasons of natural disasters (floods, droughts, fires, glacier melting, famine etc.) as well as for the reasons of imperfections of technologies or human errors there occur the crises related to land, rivers - seas and oceans, or air; unfortunately as a result of the crises we have a loss of human lives and destruction of material properties. A crisis is a follower but also a frame of life of a modern human, according to many wise men. And really, nowadays, nothing is for certain as it is crisis which has become the environment in which an individual, and organization and a society as a whole function [11].

In scientific as well as in professional circles, the term crisis is used when describing a condition with potentially negative consequences in which a modern society is. A crisis, no matter in which part of a society it happens, introduces us in the area of acting with risk. Aviation as a social activity, from its beginning until nowadays, has continuously been related to crises and acting in situations of crises. Global competition in air traffic is related to the needs of using the services with the increased quality of transport of passengers and goods, which strengthens the necessity for flexibility and creativeness by air companies [12].

Managements of air companies solve the issues of crisis management in every moment because their basic activity is a high-risk activity of air transport of people and goods. Since its complete activity occurs in a zone of high risks, air companies have essential existential necessity to function in a well-organized environment, in order to precisely plan all their activities for the purpose of realizing their strategic objectives, and within which a 
key position is occupied by the transport of people and goods, and the realized results of work in such a way provide a high competition at market and within which managing a crisis on the level of the complete business occupies a special position. In order that the idea of activities or business operation become successful in the conditions of high competition, the risk has to be constantly analyzed and controlled from all the aspects: productive, commercial, financial, market, marketing, social, political, institutional, international etc. because practically, all the mentioned risks can affect the realization of objectives and results [13]. It is indisputable that a risk as a phenomenon has existed as long as a mankind. It is a complex, constant and inevitable and uncertain phenomenon which follows the activity of every organization and in the area of aviation it follows every activity (both in the air and on land). Every air company contains risks, and they are specially pointed out during the transport of passengers and goods. They can be kept under control and minimized by introducing better organization, control and quality, improvement and rationalization of business, appropriate selection, training and simulation of pilots, choice and selection of crews, as well as the selection of personnel on land that do the support and maintenance and their constant education and training, protection at work and other measures. As a synonym to a risk, our disbelief and inability to completely predict any event, even the most certain one, occur.

Basically, there are two types of crises, "those that are managed by you and those that manage you". Proactive planning and reacting by air companies enables the managers to control and to influence them and to solve them with success, and ignoring the possibility that a crisis could occur, on the other hand, leads to the fact that a crises follow its own inertia. Making key decisions in air companies in the conditions of stress, excitement and danger caused by a crisis, is significantly more difficult than reacting to a crisis within the frames of the previously established plan for such situations. Many theoreticians, in their attempts to define it, equate a crisis management with proceeding in unpredicted situations.

A crisis can be regarded as a danger- a step to an abyss or an opportunity- a way to takeoff- progress. Anyway, there are four key factors which influence the reaction of air companies to crises: adopted strategies, established organizational structure, built organizational culture and character of the employed in an air company.
Our attitude is that the crisis management of an air company does planning in advance in order to have a ready response to all situations and to every question "what if", i.e. in order to, in case of a crisis, by applying the developed and constantly improved procedures, minimize all the possible loss and harmful consequences, and thanks to which the air company would soon return to normal condition.

The crisis management in aviation can be defined as a collection of functions, procedures or processes of which the aim is to identify, analyze and predict possible situations of crises (in a flight preparation, takeoff, flight itself as well as during landing) and to establish and develop special procedures which will enable air companies to prevent a crisis or to fight it and to overcome it with minimum damage [14]. Good crisis management of an air company has the developed procedures and trained personnel (both on land and in the air) that will apply them in any situation of crisis which can endanger an aircraft i.e. the people and goods in it.

\section{ADVANTAGES AND DISADVANTAGES OF FLIGHT SIMULATORS IN THE PROCESS OF PILOTS TRAINING}

In aviation, there has never been the question of what more important is: a plane or a flight simulator. Airplanes have indisputably always had the advantages because they do the functions of air transport of people and goods. And flight simulators have always served for training of pilots. As we have demonstrated before, the appearance of airplanes was followed close behind by the development of flight simulators, so even nowadays they are inseparable so many pilots consider them as "twins". While a plane in the air will not forgive us a mistake we do, a simulator is situated in a classroom (room) and it will enable us to practice resolving dangerous and difficult situation without being exposed to a risk and in completely safe and secure conditions.

- Safety - security: From its appearance long ago in 1910. [15] the basic concept of flight simulators has remained completely the same and it is to train in safe conditions pilots for flying tasks. Instead of explaining the safety and security of simulators it is better to regard the opinions of pilots. I strongly move forward. I reduce the pressure to the steering wheel and monitor the situation on the panels. It is all right. My left hand firmly holds the steering wheel while I am moving the handle of the gas with my right hand. 
The runaway stays behind me and I climb up to the distance of 100 feet... 300 feet... The steering wheel is completely on my... The artificial horizon revolves around. A red lights flashes, I try the turn. I have lost an engine. I do my best, I move the steering wheel on the left, I solve the problem of withdrawal and suppression. With the corner of my eye I scan the indicators. It is too slowly. I do not have enough time for another try to land. Or to land on a tree... The steering wheel is heavy, as if it was made of concrete. My hand holds a handle with effort and the pain spreads to my shoulder. I trim! I feel a firm metal wheel on my knee. The altimeter constantly turns downwards. I must not allow to fall...It happened in 1983, I saved the plane. I followed the procedures and saved the plane from an impossible situation and successfully landed. I was the only person in the plane who was hurt. My chest muscle cracked while I was fighting with the heavy commands of the flight. Even during these unrelenting, terrifying long minutes, I completely forgot that I was on the flight simulator. Yes, and all the time I was sitting on the ATC 810, in the classroom of the Aims Community College. In that period, a flight simulator was much simpler than nowadays. There were no motions, no simulation of the view outside cockpit; there were no sound effects, it was more like a box, that was a complete squadron of simulators, arranged on long desks in front of a folding chair, and their result was brilliant. They immensely helped my colleagues and me to become captains in a safe and secure way. That was more important experience than all those ones in real airplanes" [16].

- Price: The average price of a flight simulator for the planes Airbus A320 and Boeing 737 is between 10 to 12 million dollars. The average price of the planes Airbus A320 is from 100 to 125 million dollars and of Boeing 737 is approximately the same. The price of wide-body passenger airplanes, such as Airbus A350 and Boeing B787, is averagely 300 to 350 million dollars, while the flight simulators which are their support cost between 15 to 17 million dollars [17].

- The value of an hour of flight: The average value of an hour of flight on Full Motion Flight Simulators (Airbus or Boeing) is 600 dollars, contrary to it the price of an hour of flight for Boeing B737700 costs around 2,900 dollars, and for Airbus
A320 costs approximately 3,200 dollars per an hour, and Boeing 757 costs approximately 8,380 dollars per hour. The price of an hour of flight on four engine aircrafts is over 10.000 dollars [17].

- Maintenance: The average price of maintenance of flight simulators is monthly around $1.000 \mathrm{dol}-$ lars which is annually around 12.000 dollars, while the average price of maintenance of Boeing B737-700 monthly around 270.000 while annually it is around 3.000.000 million dollars [17].

- The possibility of use without limits: The concept of application of simulators is intended for using during 24 hours without limits. Crews and instructors change and the real time of using are determined by a company. Contrary to this, planes are intended to, after certain periods of time, within the resources of usage, go overhaul. These periods of times are 50, 100 and 200 hours of work [18]- Possibility of upgrading and improving the system: The concept of using a flight simulator is defined by the possibility of continuous software upgrading during the use without the interruption of engagement. On the contrary, in order to upgrade and expand the possibilities of a plane, it becomes out of use, go overhaul and upgrading of the system, which, as a consequence has the expansion of flight performances [18]- What does a flight simulator offers in training what a plane cannot: Modern simulation technologies provide the possibility of the programmed training of future pilots through gradual improvement of skills, permanent development of abilities and continuous adoption of procedures. We can do training ourselves or with instructors, who could point out how much we have made a progress, where we made mistakes, what we should pay attention to and to tell us which lessons to work out again. Modern flight simulators provide us the chance to fly to our destination a week before the planned flight, and then we can practice any approach, changing the conditions of the flight, we can even change weather conditions. Such training develops the experience of a pilot, no matter it happens in a virtual world. And instructors themselves point out that a continuous plan of skill development is much more practical in a virtual world. We can practically fly to any airport in the world by several clicks of mouse in simulation. 
The candidates have many opportunities for less time and invested money. Every training can be realized through four or five approaches in simulation, which could not be possible in a real flight. It is indisputable that the experience of real flying still represents a golden standard, but it is also true that simulation is the excellent means to learn much, to practice and adopt knowledge and skills in limited time. By maximum optimization of training on a simulator the conditions for reducing the risk of learning in real aircraft are created. Flight instructors, during the training on modern simulators, have a unique opportunity to use the pause button "Control-frick", reset the trainer for a given process, task or procedure, and to provide additional instructions, encourage and motivate a candidate, and to repeat the simulation many times, until the candidate learns it, and what is impossible to be done in a real situation of a training flight by plane [19].

\section{CONCLUSION}

Although air transport is the safest form of transport of people and goods, the example of the aircraft "Cessna 340 " on the flight from Thessaloniki to Innsbruck flown by an Austrian professional pilot with the license for instrument flights, is a typical instructional example how a harmless situation, low clouds with precipitation can cause crisis situation. Since the pilot did not pass from visual flight to instrument flight, because of the absence of his prompt reaction, the crisis got out of control.

Unfortunately, this crisis situations, which happened near Skopje, had tragic consequences. The findings of aviation investigation organs in this and in similar accidence is warning: a pass from visual conditions of flying to instrument flying is a very complex process, which is indicated by a great number of accidents that happen to the pilots out of simulators and solid training on simulators, when they try to pass from visual flying to instrumental flying.

When such and similar accidents happen, the issues related to training and practice of pilots and obtaining some aviation licenses and certificates open. Europe and America have completely appropriate law regulations regarding training and certifications for individual categories of flight as well as the categorized simulation technique by which pilots realize practice and training. Although there are clear law regulations, functional and very modern simulators and a complex procedure of obtaining aviation licenses and certificates, crisis situations in air transport that end with accidents are not rare.
That is why the findings of North Macedonian Investigation Aviation Committee warns "insufficient practice of the pilot in instrument flight is the main reason of the fall of the plane "Cessna 340" and killing the pilot and passengers" as well as the destruction of the aircraft. The logical question "How to prevent such accidents?" comes by itself.

Applying crisis management by air companies, every activity involved in the preparation of the crew and the aircraft for flight becomes more serious and more important. Crisis management in aviation can be defined as a collection of functions, procedures or processes of which the aim is to identify, analyze and predict possible situation of crisis (during the preparation of a flight, takeoff, flight itself, as well as during landing) and to establish and develop special procedures which will enable air companies to prevent crisis or to fight it and overcome it with a minimum damage.

In performing a flight, the captain of the aircraft is the key person who will apply the procedures, make the decisions and according to his/her trainings and practice, with success resolve every situation of crisis. Captains of aircrafts who are trained well and who are in top practice can experience a crisis during a flight, of course, but they have knowledge, tools, instruments and procedures of crisis management by which the crises can be recognized, fought and in the end defeated and the transport itself done accurately and on time.

The authors have the attitude that flight simulators have irreplaceable importance in the prevention of any aviation crisis situations. Not questioning the fact that training and practices on real planes still remain "golden standards", we express the opinion that modern simulators have some indisputable advantages to real planes in the process of making captains. Experienced pilots have given them the nickname "twins" wanting to point out how using modern planes is not possible without safe and secure simulator on land which supports it. Inspecting all the facts relating training planes and simulators we can make a conclusion that the practice on simulators is safer- more secure by the price of the device itself it is much cheaper, by the value of the hour of flight it is many times cheaper, by maintenance a simulator- a plane, several hundred times cheaper, they have the possibility to be used twenty-four hours a day, they have the possibility to be upgraded in a simpler way and to be improved without interrupting their functioning, they are equipped with many options of advanced training with the simulation of a great number of situation that a plane itself can perform [20]. 
The authors are conscious that they for sure haven't given all the answers related to this issue. Many questions have remained hidden and the authors themselves do not have the answer. Maybe the words of Jovo Grbic, a great expert in aviation, are the best conclusion to this project: "Aviation is not unsafe, but it is like a sea, unforgivable to any carelessness or negligence." [21].

\section{REFERENCES}

[1] Z. Vereš, "When the engines shut down", "Kad motori utihnu”, KIA More, Beograd, 2007.

[2] A. Kusovac, "News in a training of flight techicians", "Novine u školovanju vazduhoplovnih mehaničara", Aeromagazin, vol. 4, 1988, pp 13.

[3] Federal Aviation Administation, "FAR 121 Subpart N-Training Programe", FAA, Washington D.C, 2013.

[4] S. Parson, "In Celebration of Simulation", FAA Safety Briefing, 2017, pp. 7-8.

[5] T. Hoffmann, "Sorting the Lot of Flight Simulation Devices”, FAA Safety Briefing, 2017, pp. 8-13.

[6] Federal Aviation Administration, “AC-61-136A Apendix 1 and 2", FAA, Washington D.C., 2014.

[7] T. Hoffmann, "Sorting the Lot of Flight Simulation Devices”, FAA Safety Briefing, 2017, pp. 8-13.

[8] Federal Aviation Administration, "AC-61-136A Apendix 1 and 2", FAA, Washington D.C., 2014.

[9] Joint Aviation Authority, "Aeroplane Flight Training Devices”, JAA, Hoofddorp, Netherlands, 2008.

[10] S. D. Beard, "Space Shuttle Landing and Rollout Training at the Vertical", American Institutet of Aeronautics and Astronautics, 2014, pp. 16.

[11] V. Grujić, G. Vukadinović, "Crisis management of small and midium bussineses", "Krizni menadžment malih i srednjih preduzeća”, "Management 2012”, MESTE FBIM Transaction, Belgrade, Serbia, 2012, pp. 236-243.

[12] V. Grujić, D. Lazić, "The Final Phase of the Flight of the Aircraft as an Element of the Crisis Management in Aviation", Završna faza leta vazduhoplova kao element kriznog menadžmenta u vazduhoplovstvu“, vol I, FBIM Transaction, Belgrade, Serbia, 2013, pp. 111-121.

[13] V. Grujić, D. Lazić, “The Significante of the Crisis Management in Preparation of the Pilot", "Značaj primene kriznog menadžmenta u pripremi pilota”, FBIM Transaction, Belgrade, Serbia, 2014, pp. 141-154.

[14] V. Grujić, D. Lazić, “The Significante of the Crisis Management in Preparation of the Pilot", "Značaj primene kriznog menadžmenta u pripremi pilota”, FBIM Transaction, Belgrade, Serbia, pp. 2014, 141-154.
[15] C. E. Crossman, "Dry Shooting for Airplane Gunners", Popular Science, 2019, pp. 13-14.

[16] W. E. Dubois, "Rusty Pilot Seminars", Retrived from http://planetaless.net, 2012.

[17] Airbus Group, "New Airbus aircraft list prices for 2016", Retrieved from: http://www.airbus.com/ newsroom/press-releases/en/2016/01/new-airbusaircraft-list-pricesfor-2016.html.

[18] W. E. Dubois, "Rusty Pilot Seminars", Retrived from http://planetaless.net, 2012.

[19] Federal Aviation Administration, "The Limits of Simulations”, FAA Safety Briefing, 2017, pp. 12-13.

[20] J. Wiliams, “A Virtual Plan for the Real World How Simulation Can Help You Mitigate Risk”, FAA Safety Briefing, 2017, pp. 21-23.

[21] J. Grbic, "Flight Safety", "Bezbednost vazdušne plovidbe“, JAT Airways, Belgrade, Serbia, 1978. 